\title{
Archaeology and Anthropology - Focused on Some Similarities in Differences Between Animals and Humans
}

\author{
Strauss DFM* \\ School of Philosophy, Northwest University, South Africa \\ Submission: May 25, 2019; Published: June 21, 2019 \\ *Corresponding author: Strauss DFM, School of Philosophy, Northwest University, South Africa
}

\section{Perspective}

This article will focus on the picture emerging from scholarship produced during the $20^{\text {th }}$ century. The dominant trends maintain the Darwinian belief in die continuity between the main groups of animals and of human beings. Yet, during the seventies of the previous century mainly palaeontologists started to question this picture for during the last sixty years an increasing challenge to the classical Darwinian conception of a gradually and continuous transition through numberless incrementally small changes over millions of years was questioned by palaeontologists such as Gould, Eldredge and Kitts. This challenge flows from what Gould and Eldredge characterized as the dominant theme of the fossil record, namely stasis (constancy or fixity). One may capture the core of this issue by employing the opposition of continuity versus discontinuity. The clear predominance of an empirical pattern of stasis and "abrupt geological appearance as the history of most fossil species has always been acknowledged by palaeontologists and remains the standard testimony... of the best specialists in nearly every taxonomic group. In Darwinian traditions, this pattern has been attributed to imperfections of the geological record that impose this false signal upon the norm of a truly gradualistic history. Darwin's argument may work in principle for punctuational origin, but stasis is data and cannot be so encompassed".

To this one can add the following statement of Gould He states: "The extreme rarity of transitional forms in the fossil record persists as the trade secret of paleontology. The evolutionary trees that adorn our textbooks have data only at the tips and nodes of their branches; the rest is inference, however reasonable, not evidence of fossils". He and Eldredge questions the escape route to "imperfection". "The fossil record may, after all, be 99 percent imperfect, but if you can, nonetheless, sample a species at a large number of horizons well spread over several million years, and if these samples record no net change, with beginning and end points substantially the same, and with only mild and errant fluctuation among the numerous collections in between, then a conclusion of stasis rests on the presence of data, not on absence". Kitts declares: "Evolution requires intermediate forms between species and paleontology does not provide them".

Also, Portman recognized the general spiritual climate within Darwinian circles by 1900: "The mood of the time, one of optimism [is] based on a biologically grounded faith in continuous advancement ..." [1]. And in his last large work from 2002 Gould argues against the continuity postulate: "These stories begin from the same foundational fallacy and then proceed in an identically erroneous way. They start with the most dangerous of mental traps: a hidden assumption, depicted as self-evident, if recognized at all - namely, a basic definition of evolution as continuous flux". Challenging the discontinuity between animals and human beings is normally accompanied by the claim that animals, like humans, can obtain concepts, that they do make and use tools, and that they do have language.

In a relatively simplistic fashion, we have become accustomed to distinguishing between nature and culture. The former encompasses material things, plants, animals and what they can produce (such as the web of the spider, the nests of birds, and so on). Owing to the so-called linguistic turn it often happens that a reduced understanding of culture is advanced, such as found in the thought of Dikovitskaya who circumscribes culture as a "representational, symbolic and linguistic system" [2]. Znanieki captures much more in his employment of the term culture: "The concept which this term symbolizes includes religion, language, literature, art, customs, mores, laws, social organization, technical production, economic exchange, and also philosophy and science" [3]. Although this definition practically touches upon every normative aspect of reality, from the logical-analytical up to the fiduciary or certitude aspect, it may be wise to avoid making culture just another basket-term for all forms of normativ- 
ity, similar to what happened to the ethical which is normally equated with all forms of normativity. There is no highest genus of normative aspects, such as the concept of culture, with the specific aspects as the various species of this genus, such as the sign mode, die social aspect, the economic, the aesthetic or jural aspects.

We may also note that the a priori continuity postulate of neo-Darwinism suggests that since animals and humans are basically "similar," they ought to have comparable capacities in respect of thinking, tool making and language. Yet even leading neo-Darwinists, such as Bernard Rensch, had to admit that animals lack argumentative logical skills. Others maintain that animals can form unnamed concepts or of partaking in unnamed thinking. A simple test, refuting this entire enterprise, is to ask if animals and the anthropoids (orangutan, gorilla, chimpanzee and gibbon) can acquire illogical concepts, such as that of a square circle (originally employed by Kant) [4]? An attempt at Münster to get chimpanzees to copy drawings of squares and triangles lasted six months and met with no success. How then could a chimpanzee be brought to acquire the concept of a "square circle", or even to realize that it is illogical?! This also shows that the discontinuity between animals and humans is given in the normativity of the post-sensory modes of experience (aspects). By virtue of the normative structure of the logical and post-logical aspects human functions within them as subjects presupposes an accountable free will, the freedom to choose. Accountability embodies an analogy (backward pointing retrocipation) within the logical sphere, reflecting the causal relation present within the foundational physical aspect. Contraries such as logical illogical, clear - confused, polite - impolite, legal - illegal, moral - immoral and so on) mark the irreducibility of the normed structure of human actions taking place under the guidance of any normative aspect.

In fact, non-scientific concepts are conceptual representations. Animals lack the ability to form genuine (logical or illogical) concepts. In addition, they lack the uniquely human capacity of imaginativity. Humans are even able to convert what is not visible into conceptual representations. Eibl-Eibesfeldt speaks of the spatial intelligence of human beings which, for him, highlights the ability to "grasp" spatial relationships in a centred way. He holds that our thinking is spatial, combined with the ability to translate invisible relationships into conceptual representations [5]. This opens the way to what is individual. Mäckler mentions the following definition of art by Benedetto Croce: "Art is intuition, intuition is individuality and individuality does not repeat itself" [6]. Human knowing appears to be co-conditioned by the two fundamental dimensions of reality, the knowing of modal aspects and knowledge of entities. The former is known through functional relations and the latter through imaging that takes on the shape of imagining in the uniquely human acquaintance with the world. These two legs of knowing - modally directed and entitary directed - imply each other and open the way to account for our knowledge of universality and individuality. Just compare the conceptions of Croce. He states that knowledge has two forms: it is either intuitive knowledge or logical knowledge; knowledge obtained through the imagination or knowledge obtained through the intellect; knowledge of the individual or knowledge of the universal; of individual things or of the relations between them: it is, in fact, productive either of images or of concepts.

Surely imaginativity, as the manifestation of a specific directedness of human knowing towards the dimension of (individual) entities, extends across this entire dimension and cannot be restricted to aesthetic imaginativity alone - as suggested by Seerveld [7]. Eibel-Eibesfeldt mentions that Arnold Gehlen is justified in calling the human being a "Phantasiewesen," a being characterized by the ability to imagine [5]. In addition, the flexibility of human understanding allows for a cross-utilization of the two dimensions of human experience, since the modal aspects serve as points of entry to an understanding of entities whereas the nature of the modal aspects can only be explained with the aid of metaphors - the result of imaginatively relating different kinds of entities through predication (sometimes mediated by images depicting relationships between entities and aspects or aspects and entities). Although neo-Darwinists claim that animals and humans are similar because animals not only use tools but make them as well, archeologists emphasize the human formative imagination which is capable to invent something different from what is presented to the senses [8]. This view is complementary to Kant, who defines the Einbildungskraft (imagination) as the capacity to have a representation of an object without its presence to the senses [4]. This enables human beings to have a historical awareness: memory (historical past) and expectations or planning (historical future) - while animals are said to live in the present, the now.

From the fact that animals not only use tools but also "manufacture" them it may look as if animals actively function within the cultural-historical aspect. The distinct way in which human tool making differs from animal tool making follows from a second meaning attached to the word imagination, namely the ability to imagine something that is present to the senses different from the way in which it is given. Both forms of the imagination have their foundation is the typical human free formative fantasy. Applied to the problem of tool making the archaeologist Narr specified three distinct criteria in order to highlight what is typical human in respect of human tool making. The form, function and manner of production ought not to be suggested by what is given - like stripping the leaves from a branch $[9,10]$. In conclusion we may point out that there are inherent anatomical limitations preventing animals from producing articulate (human) speech. What is unique about human language?

It is commonly assumed that because animals have different forms of communication, they use language. Suppose a magnate 
is used to make a non-magnetic piece of iron magnetic? In this case the magnetism of the magnet is communicated to another piece of iron. Does this mean that two physical subjects employed language? Likewise, when the genetic code is duplicated to offspring, does it mean that we may here identify a kind of biotic language between different living entities? And what about the dance of the bees? The latter is indeed quite remarkable, because by means of the (i) tempo, (ii) direction and (iii) angle of the figure eight performed, the (i) distance, (ii) location, and (iii) direction of the source is depicted [5]. Eibl-Eibesfeldt does provide an addition al explanation. The speed of the wind is incorporated in the dance tempo - if the bees must fly against the wind the dance is slower, indicating a larger distance. The distance-indication is neither related to the real distance, nor to the duration of the flight, but to the effort (force) needed to achieve the goal [5].

The first point to be observed is that in the communication between bees the elements of the dance are always identical, they always have the same "meaning." All human utterances, by contrast, can signify several different things, depending on the context, intention, or even, in the case of written language, the punctuation. Language therefore presupposes responsible and free human activities which require accountable choices between multiple options. This is absent amongst animals. Eibl-Eibesfeldt states that that "which, by contrast, regarding animals, is generally designated as 'language', exclusively moves within ... the domain of interjection, of the expression of moods lacking insight." He also categorically affirms that "the capacity of lingual communication is specifically human" and that "nothing really comparable is found in the realm of animals" [5]. The logical-analytical mode with its freedom of choice is presupposed in language because the interpretation needed presupposes freedom of choice [11-13]. Eibl-Eibesfeldt also holds that the sharing of emotional conditions does not need a word-language, but that speaking presupposes a certain distancing from emotions [5].

\section{The Anatomical Limitations Precluding Animal Speech}

Post-mortem studies of the upper respiratory tract in mammals, as well as cineradiographic studies, have shown that the position of the larynx is crucial in determining the way in which an individual breathes, swallows and vocalizes [14]. This implies that there are certain anatomical peculiarities that go hand in hand with the contribution of brain functioning in the production of human speech; the gradual descent of the larynx after the post-natal period [15]. The 'humanlike' apes (anthropoids, i.e. the orangutan, gorilla, chimpanzee, and gibbon), are, as a result of anatomical shortcomings, born incapable of speech. In order to provide the newborn human suckling with a milk tract separate from the respiratory tract, the position of the human larynx at birth is the same as that of mammals. In the period between the first and second year, this highly positioned larynx starts its descent in the neck. This downward movement creates the pharynx cavity, necessary for the articulation of the richer voice disposition in human beings. Laitman declares that the precise time this shift occurs, as well as the physiologic mechanisms that underlie it, are still poorly understood [14]. As soon as the larynx reaches its destined low position, it can no longer lock into the nasopharynx. Consequently, the respiratory and digestive pathways cross above the larynx. This creates the possibility of suffocating, which surely is, evaluated, something negative.

However, it is precisely this expanded pharynx that provides human beings with the unique potential to produce a rich variety of speech sounds. The palate between the mouth and nose cavities serves as basis for the resonance of the sounds produced. Goerttler even mentions the fact that, in the third month after conception, a distinctively human structural element develops [16]. It is interesting in this connection that Laitman informs us that the basicranial similarities between the australopithecines and extant apes suggest that their upper respiratory tract was also similar in appearance. Consequently, as with living nonhuman primates, the pharynx portion for sound modification in these early hominids would have been greatly restricted: As a result, these early hominids probably had a very restricted vocal repertoire as compared with modern adult humans. For example, the high larynx would have made it impossible for them to produce some of the universal vowel sounds found in human speech patterns [14]. If we define a speech organ as that bodily part which exists solely in service of the production of speech sounds, then a surprising fact is that there are no human speech organs. Let us enumerate possible candidates: the lungs, larynx, mouth cavity, palate, teeth, lips and nose cavity. Without exception, all these organs perform primary functions that would continue to function in their normal way even if human beings never uttered a single word [17]! Human language simply takes hold of all these different organs in the production of speech sounds ("body language" or "sign language" employs different parts of the body).

This highly developed and subtle cooperation, especially of three organs so heterogeneous in character as the mouth, the larynx and the brain, integrated in the production of human speech sounds, makes it rather difficult, if not hopeless, to provide us with a causal evolutionary explanation of this astonishing phenomenon. The question arises, what number of miraculous changes should have occurred to produce the articulation conditions necessary for truly human language formation? Overhage states: Such an unfathomable process of change affecting so many differently structured organs and organ complexes, closely correlated with each other, should have proceeded harmoniously as a total change, if it was to come to the unprecedented perfection of human speech [17]. Although more recent research discovered that frequency plays a relatively important role in language acquisition, the claim of Chomsky, 
namely that an "a priori" element dominates the human capacity to master a language, should still be accounted for.

Stegmüller employs a neat comparison in order to explain Chomsky's understanding of this issue. He compares acquiring / mastering a language with the complexities involved in studying differential geometry and quantum physics. Whereas it would seem to be far-fetched to believe that a two-year old boy is mastering the said disciplines, no one considers it strange to hear that such a boy is mastering his mother tongue. Chomsky appeals to empirical arguments in support of his view that learning an ordinary language presupposes an a priori element.

\section{Strauss Summarizes his View as Follows}

He considers the mastery of a grammatical structure and of linguistic rules from insufficient linguistic data. Even a child can generate more sentences than there are seconds in the life of any average person. Keeping in mind the comparison between mastering a complex scientific theory and learning a language, one should imagine that differences in intelligence would be significant in the former case, but strangely enough the same does not apply to language acquisition, for large differences in intelligence result in negligible differences in linguistic competence. Furthermore, even if the linguistic experience to which the child is exposed is not only limited but also largely degenerate, the child nonetheless masters the principles and rules governing the formation of meaningful sentences and the interpretation of linguistic utterances. Perhaps even more remarkable is the fact that language is learned during a stage in which the child is not capable of achieving anything comparable. The absence of any direct instruction and above all the fact that many children succeed in learning to speak without actively participating in talking activities ought to be mentioned as well. Besides, once the basic linguistic competency is mastered the child can creatively generate meaningful sentences never heard before - ruling out any idea that language merely emerges through acts of imitating what is heard. All-in-all these considerations are used by Chomsky in support of his claim that an a priori element is inherent in the faculty of language-acquisition $[18,19]$. Clearly, the dominant neo-Darwinian gradualism is still confronted with serious difficulties. Resolving them may be one of the main challenges of future scientific investigations [20-24].

\section{References}

1. Portmann A (1990) A zoologist looks at humankind, translated by Judith Schaefer. Columbia University Press, New York, USA.

2. Dikovitskaya M (2005) Visual culture: the study of the visual after the cultural turn. MIT Press, Cambridge, UK.

3. Znanieki F (1963) Cultural Sciences, their origin and development, University of Illinois Press, Urbana, USA.
4. Kant I (1783) Prolegomena einer jeden künftigen Metphysik die als Wissenschaft wird auftreten können. [Prolegomena to every future Metaphysics that may Operate as a Science] Felix Meiner edition, Hamburg, Germany.

5. Eibl-Eibesfeldt I (2004) Grundriß der vergleichenden Verhaltensforschung, Ethologie, [Overview of a Comparative study of Animal Behaviour, Ethology] $8^{\text {th }}$ revised Edition. Buch Vertrieb Blank GmbH, Vierkirchen-Pasenach, Germany.

6. Mäckler A (2000) 1460 Antworten auf die Frage: was ist Kunst? DuMont, Köln, Germany.

7. Seerveld CG (1968) A Christian Critique of Art and Literature. The Association for Reformed Scientific Studies, Toronto, Canada.

8. Narr KJ (1976) Cultural Achievements of Early Man.

9. Narr KJ (1974) Tendenzen in der Urgeschichtsforschung. In: Luyten NA (Eds.), Germany.

10. Narr KJ (1976) Cultural Achievements of Early Man.

11. Nida EA (1979) Componential analysis of Meaning. Mouton, New York, USA.

12. De Klerk WJ (1978) Inleiding to die Semantiek. Butterworth, Durban, South Africa.

13. Lyons J (1969) Introduction to Theoretical Linguistics. Cambridge University Press, Cambridge, UK.

14. Laitman JT (1985) Evolution of the upper respiratory tract: The fossil evidence.

15. Portmann A (1973) Der Weg zum Wort. In: ERANOS, Leiden, Netherlands, p. 39.

16. Goerttler K (1972) Morphologische Sonderstellung des Menschen im Reich der Lebensformen auf der Erde. In: Gadamer \& Vogler, 2: 215257.

17. Overhage P (1972) Der Affe in dir, Frankfurt am Main: Josef Knecht, Germany.

18. Strauss DFM (2009) Philosophy: Discipline of the Disciplines, Paideia Press, Grand Rapids, USA.

19. Ellis NC (2002) Frequency Effects in Language Processing, A Review with Implications for Theories of Implicit and Explicit Language Acquisition, Bangor: University of Wales, SSLA 24: 143-188.

20. Altner G, Hofe, H (1972) Die Sonderstellung des Menschen. Gustav Fischer Verlag, Stuttgart, Germany.

21. Gadamer HG, Vogler P (1972) Neue Anthropologie, Georg Thieme, Germany.

22. Luyten NA (1974) Fortschritt im heutigen Denken? Publication of the "Görres-Gesellschaft für Interdisziplinäre Forschung"; Series: Grenzfragen, Alber, Freiburg, Germany.

23. Narr KJ (1973) Kulturleistungen des frühen Menschen

24. Tobias PV (1985) Hominid Evolution. Liss, New York, USA.

25. Gould, S.J. (2002) The Structure of Evolutionary Theory. Cambridge, Massechusettes: The Belknap Press of Harvard University Press 
his work is licensed under Creative Commons Attribution 4.0 License DOI: 10.19080/GJAA.2019.09.555774

\section{Your next submission with Juniper Publishers} will reach you the below assets

- Quality Editorial service

- Swift Peer Review

- Reprints availability

- E-prints Service

- Manuscript Podcast for convenient understanding

- Global attainment for your research

- Manuscript accessibility in different formats

( Pdf, E-pub, Full Text, Audio)

- Unceasing customer service

Track the below URL for one-step submission https://juniperpublishers.com/online-submission.php 